\title{
STUDI KOMPARATIF : TEORI EDWARD LEE THORNDIKE DAN IMAM AL GHAZALI DALAM IMPLEMENTASINYA DI PEMBELAJARAN ANAK USIA DINI
}

\author{
Nur Kolis ${ }^{\text {a, }}$, Aisyah Fajar Putri Artini ${ }^{\text {b, }, \text {, }}$ \\ a,b Pondok Pesantren Tahfidzul Qur'an Ibnu Abbas Klaten, Indonesia \\ ${ }^{1}$ nurkoliss012@gmail.com ${ }^{2}$ fajarputriartiniaisyah@gmail.com
}

\begin{tabular}{l}
\hline Informasi artikel \\
\hline Received : \\
Januari 30, 2022. \\
Revised : \\
Februari 13, 2022. \\
Publish : \\
Maret 03, 2022. \\
Kata kunci: \\
Teori Belajar Anak \\
Usia Dini; \\
Trial and Error; \\
Akhlak;
\end{tabular}

Keywords:

Early Childhood

Learning Theory;

Trial and Error;

Morals;

\begin{abstract}
ABSTRAK
Belajar bukan hanya sekedar proses pemindahan ilmu (transfer of knowledge), tetapi juga merupakan transformasi atau perubahan (transformation); baik itu pengetahuan, keterampilan, dan nilai (value). Terdapat beberapa teori belajar yang telah dicetuskan oleh tokoh-tokoh baik dari Barat maupun Islam untuk mewujudkan pembelajaran yang efektif. Teori belajar Edward Lee Thorndike lebih menekankan pada peristiwa belajar yang bisa diterima oleh akal dan dapat dibuktikan melalui pancaindera (rasional-empiris). Sedangkan teori belajar yang diusung oleh $\mathrm{Al}$ Ghazali tidak hanya memberikan perhatian pada peristiwa belajar yang bersifat rasional-empiris, akan tetapi juga memberikan perhatian yang bersifat normatif-kualitatif. Proses belajar trial and error yang dilakukan dengan memberikan stimulus untuk mendapatkan respon yang diharapkan bisa dipakai untuk memberikan motivasi belajar anak usia dini. Selain itu, agar bukan sekedar mekanistik mengingat anak bukanlah robot yang tidak memiliki rasa, maka anak juga harus dibekali dengan nilai-nilai religius yang bisa memberikan motivasi dari dalam diri anak itu sendiri. Karena tugas pendidik adalah membantu anak mengembangkan seluruh potensi yang ia miliki hingga mencapai kedewasaan yang akan dirumuskan oleh pendidik baik metode maupun materi haruslah mengacu pada anak yaitu pada aspek perkembangannya yang selalu berdasarkan pada pembentukan akhlak.

\section{ABSTRACT}

Learning is not just a process of transferring knowledge (transfer of knowledge), but also a transformation or transformation; be it knowledge, skills, and values. There are several learning theories that have been coined by figures from both the West and Islam to realize effective learning. Edward Lee Thorndike's learning theory emphasizes more on learning events that can be accepted by reason and can be proven through the five senses (rational-empirical). While the learning theory promoted by Al Ghazali not only pays attention to rational-empirical learning events, but also pays attention to normative-qualitative ones. The trial and error learning process is carried out by providing a stimulus to get a response that is expected to be used to provide motivation for early childhood learning. In addition, so that it is not just mechanistic considering that children are not robots that do not have feelings, children must also be equipped with religious values that can provide motivation from within the child itself. Because the task of educators is to help children develop all the potential they have until they reach maturity, which will be formulated by educators, both methods and materials must refer to children, namely on aspects of their development which are always based on moral formation.
\end{abstract}

This work is licensed under a Creative Commons Attribution-ShareAlike 4.0 International License. Allows readers to read, download, copy, distribute, print, search, or link to the full texts of its articles and allow readers to use them for any other lawful purpose. 


\section{PENDAHULUAN}

Belajar merupakan sebuah kebutuhan yang wajib dipenuhi oleh setiap manusia untuk menjalani kehidupannya. Belajar memegang peranan yang sangat penting bagi manusia sebab segala sesuatu membutuhkan ilmu. Proses belajar tidak terbatas waktu dan tempat, manusia bisa belajar sepanjang waktu yang dimilikinya (long life education), baik itu di lembaga pendidikan atau di luar lembaga pendidikan.

Menurut Hermansyah (2020) kegiatan belajar mengajar adalah satu kesatuan dari dua kegiatan yang searah. Kegiatan belajar adalah kegiatan primer yang dilakukan oleh peserta didik, sedangkan kegiatan sekunder mengacu pada kegiatan pendidik. Oleh karena itu belajar dan pembelajaran menjadi dua hal yang saling berkaitan erat dan tak terpisahkan.

Belajar bukan hanya sekedar proses pemindahan ilmu (transfer of knowledge), tetapi juga merupakan transformasi atau perubahan (transformation); baik itu pengetahuan, keterampilan, dan nilai (value). Oleh karenanya belajar bisa dikatakan ideal jika proses belajar itu menyetuh tiga ranah, yaitu kognitif, psikomotorik, dan afektif. Dengan begitu belajar bukan hanya sekedar pemenuhan intelektual, tetapi juga mampu memberikan perubahan tingkah laku pada individu.

Kesiapan dalam belajar dan mengajar yang dimiliki oleh setiap anak dan pendidik menjadi penting demi tercapaian hasil pembelajaran yang optimal. Terdapat beberapa teori belajar yang telah dicetuskan oleh beberapa tokoh untuk mewujudkan pembelajaran yang efektif. Teori-teori belajar tersebut ada yang dicetuskan oleh tokohtokoh yang berasal dari Barat seperti Edward Lee Thorndike (behaviorisme), Abraham Maslow (humanisme), Jean Piaget (kognitivisme), dan juga dari kalangan tokoh Islam seperti Al Ghazali (pendidikan akhlak), Ibnu Miskawaih dan lainnya.

Dalam pandangan Thorndike pembelajaran berorientasi pada hasil yang dapat diukur dan diamati, serta kesalahan harus segera diperbaiki. Pengulangan dan latihan digunakan supaya perilaku yang diinginkan dapat menjadi kebiasaan. Hasil yang diharapkan dari penerapan teori behavioristik ini adalah terbentuknya suatu perilaku yang diinginkan. Dimana perilaku yang diinginkan mendapat penguatan positif dan perilaku yang kurang sesuai, mendapat penghargaan negatif. Dalam hal ini, evaluasi atau penilaian didasari atas perilaku yang tampak/kelihatan. 
Penerapan teori behavioristik Thorndike yang salah dalam suatu situasi pembelajaran juga mengakibatkan terjadinya proses pembelajaran yang sangat tidak menyenangkan bagi siswa yaitu guru sebagai sentral, bersikap otoriter, komunikasi berlangsung satu arah, guru melatih dan menentukan apa yang harus dipelajari anak. Anak dipandang pasif, perlu motivasi dari luar, dan sangat dipengaruhi oleh penguatan yang diberikan guru. Anak hanya mendengarkan dengan tertib penjelasan guru dan menghafalkan apa yang didengar dan dipandang sebagai cara belajar yang efektif. Penggunaan hukuman yang sangat dihindari oleh para tokoh behavioristik justru dianggap sebagai metode yang paling efektif untuk menertibkan siswa.

Pendidikan anak dalam pandangan Al-Ghazali tentu tidak berbeda dengan tujuan pendidikan secara umum yaitu untuk mendekatkan diri kepada Allah. AlGhazali mengatakan bahwa sungguh aku telah mengetahui bahwa sesungguhnya buah ilmu adalah kedekatan dengan Tuhan semesta alam. Jadi tujuan pendidikan anak adalah : Pengembangan jasmani dan rohani sebagai sumber kebahagiaan dunia.

Dasar atau sumber yang dijadikan pijakan pendidikan Al-Ghazali sama dengan dasar pendidikan Islam, yakni Al-Qurean, AsSunnah dan dilengkapi oleh Atsaru AshShobahah. Dasar-dasar pendidikan anak yang menjadi pijakan Al-Ghazali dalam mrumuskan segala sesuatu yang berhubungan dengan pendidikan anak. Terkait tujuan pendidikan Al-Ghazali mengatakan jika anak dibiasakan dan diajarkan berbuat baik maka ia akan memiliki kecenderungan untuk berbuat baik sampai ia dewasa atau bahkan sampai tua. Hal itu terjadi karena nilai-nilai kebaikan telah meresap dalam dirinya dan telah menjadi pola pikir, sikap dan perilakunya.

Peneliti mengkaji teori belajar perspektif Barat khususnya yang dicetuskan oleh Edward Lee Thorndike dan teori belajar perspektif Islam yang dicetuskan oleh Al Ghazali dalam implimentasinya di pembelajaran anak usia dini.

\section{METODE}

Metode yang digunakan dalam penelitian ini adalah library research (penelitian kepustakaan). Kajian pustaka berusaha mengungkapkan konsep-konsep baru dengan cara membaca dan mencatat informasi-informasi yang relevan dengan kebutuhan. Teknik pengumpulan data dalam penelitian ini penulis melakukan identifikasi wacana melalui buku, artikel, jurnal, maupun informasi lain yang berkaitan 
dengan tema pembahasan mengenai teori belajar perspektif Edward Lee Thorndike dan Al Ghazali dalam implikasinya di pembelajaran anak usia dini. Karena penelitian ini berbentuk library research, maka dalam pengumpulan data digunakan metode dokumentasi. Selanjutnya data-data yang telah terkumpul dianalisis menggunakan content analysis (analisis isi) atau tekstual dalam studi kepustakaan secara interpretasi terhadap isi pesan suatu komunikasi yang terungkap dalam literatur-literatur yang memiliki relevansi dengan tema penelitian ini.

\section{HASIL DAN PEMBAHASAN}

\section{Teori belajar}

Menurut Mulyono (2012) teori merupakan seperangkat prinsip atau kaidah tentang suatu fenomena alam atau sosial yang telah diuji kebenarannya oleh banyak pihak dan dapat digunakan sebagai alat untuk merumuskan serta memprediksi fenomena yang sama di tempat dan waktu yang berbeda.

Belajar sebagaimana dinyatakan oleh Thoifuri (2013) adalah suatu proses untuk mendapatkan pengetahuan, baik dilakukan oleh perorangan, kelompok, maupun dengan bimbingan guru sehingga perilakunya berubah. Adapun maksud dari perilaku adalah kebiasaan individu, baik yang berupa pengetahuan, sikap, pemahaman, maupun keterampilan. Aprida Pane dan Muhammad Darwis (2017) juga mengatakan bahwa belajar adalah proses perubahan perilaku yang disebabkan interaksi antara individu dengan lingkugannya yang bersifat terus menerus secara dinamis, fungsional, positif, aktif, dan terarah.

Berdasarkan pengertian belajar yang telah disebutkan di atas, maka dapat disimpulkan bahwa belajar adalah sebuah proses perubahan menuju ke arah yang lebih baik dan dilakukan secara terus menerus. Oleh karena itu diperlukan metode atau teori belajar yang efektif agar tujuan belajar dapat tercapai dengan maksimal.

Teori belajar menurut Chairul Anwar (2017) merupakan upaya untuk mendeskripsikan cara belajar manusia. Teori belajar muncul seiring penelitian dan pengamatan terhadap objek makhluk hidup (manusia dan hewan) tentang cara belajar makhluk hidup terhadap lingkungannya. Dari penelitian dan pengamatan tersebut, kemudian ditemukan pengertian dan konsep tentang belajar atau teori belajar. Dari 
situlah kita mengenal bermacam-macam teori belajar menurut penelitian dan penemuan para tokoh penemunya.

Novi Irwan Nahar (2016) juga mendefiniskan bahwa teori belajar adalah kumpulan dari beberapa prinsip yang saling berhubungan serta penjabaran dari fakta atau penemuan-penemuan yang terjadi saat proses belajar. Izzatur Rusuli (2014) menyebutkan bahwa teori belajar terbagi menjadi tiga, yaitu: teori behavioristik, kognitif, dan humanisme. Teori belajar behavioristik menekankan kajiannya pada pembentukan tingkah laku yang berdasarkan hubungan antara stimulus dengan respon yang bisa diamati dan tidak menghubungkannya dengan kesadaran maupun konstruksi mental. Teori ini berlawanan dengan teori kognitif yang menyatakan bahwa proses belajar adalah proses mental yang tidak dapat diamati secara kasat mata. Adapun teori humanistik merupakan teori yang mencoba menengahi antara teori behavioristik dengan kognitif.

Selain teori-teori belajar yang telah disebutkan di atas, masih terdapat teoriteori belajar yang dicetuskan oleh tokoh-tokoh yang lain tak terkecuali oleh tokoh Islam seperti Al Ghazali. Jika teori-teori behavioristik lebih menekankan rasio dan empiris, maka teori-teori yang digagas oleh tokoh Islam tidak hanya menekankan pada rasio dan empiris, tetapi juga normatif-kualitatif yang didasarkan pada al Qur'an dan sunnah.

Menurut Chairul Anwar (2017) aliran behaviorisme lahir pada tahun 1900-an dari sebuah gagasan awal bahwa perilaku dapat dipelajari dan dijelaskan secara ilmiah. Dalam melakukan penelitian, behavioris bukan mempelajari keadaan mental individu, melainkan perilakunya sehingga disebut behavior. Jadi, karakteristik esensial dari pendekatan behaviorisme terhadap belajar ialah pemahaman terhadap peristiwaperistiwa di lingkungan untuk memprediksi perilaku seseorang, bukan pikiran, perasaan, ataupun kejadian internal dalam diri orang tersebut. Fokus behaviorisme ialah respon terhadap berbagai tipe stimulus. Aliran ini mengambil kesimpulan dari berbagai penelitiannya terhadap hewan, dan menerapkan hasil belajarnya terhadap manusia.

\section{Edward Lee Thorndike dan Teori belajarnya}

Edward Lee Thorndike lahir pada 31 Agustus 1874 dan meninggal pada 9 Agustus 1949, ia adalah seorang ahli psikologi asal Amerika Serikat yang berkarir di 
Columbia University (Ali Makki, 2019). Thorndike lahir di Williamsburg, Massachusetts. Ia merupakan anak dari seorang pendeta Metodis di Lowell, Massachusetts. Ia lulus dari The Roxbury (1981), di West Roxbury, Massachusetts dan Wesleyan University (1895). Ia kemudian mendapatkan gelar M.A. di Harvard University pada tahun 1897. Pada tahun 1898, ia menyelesaikan Ph.D. di Columbia University (Chairul Anwar, 2017).

Edward Lee Thorndike berpendapat bahwa dasar belajar adalah asosiasi antara kesan pancaindra (sense impresion) dengan implus untuk bertindak. Asosiasi yang demikian disebut connecction (koneksi) atau bond. Hal itulah yang menjadikan lebih kuat atau lemah dalam terbentuknya pembelajaran atau hilangnya kebiasaankebiasaan. Karena prisnsip itulah teori Edward Lee Thorndike disebut dengan connection atau bond psykology (Hermansyah, 2020). Thorndike mengemukakan bahwa tipe pembelajaran yang paling fundamental adalah pembentukan asosiasiasosiasi (koneksi-koneksi) antara pengalaman inderawi (persepsi terhadap stimulus atau peristiwa) dan implus-implus saraf (respon-respon) yang memberikan manifestasinya dalam bentuk perilaku. Edward Lee Thorndike meyakini bahwa pembelajaran sering terjadi melalui rangkain eksperimen trial and error (Hermansyah, 2020).

Ali Makki (2019) berpendapat bahwa teori belajar yang paling tua adalah teori asosiasi, yakni hubungan antara stimulus dan respon. Hubungan itu bertambah kuat apabila sering diulangi dan respon yang tepat diberi ganjaran berupa makanan atau pujian dan cara lain yang memberi kepuasan dan kesenangan.

Chairul Anwar (2017) menyebutkan bahwa Edward Lee Thorndike merupakan tokoh yang mengembangkan dan memopulerkan teori koneksionisme. Dalam teorinya, ia mengemukakan kalau proses belajar hewan memiliki kesamaan dengan proses belajar manusia. Kesamaannya terletak pada hubungan (koneksi atau asosiasi) antara kesan yang ditangkap oleh pancaindra (stimulus) dengan perbuatan (respon). Oleh karenanya, teori ini disebut dengan teori stimulus (S)-respone (R).

Edward Lee Thorndike melakukan percobaan terhadap seekor kucing sebagai subjek penelitiannya. Kucing itu lalu dimasukkan kedalam sebuah kotak dengan konstruksi pintu kurungan yang sedemikian rupa. Ketika kucing menyentuh tombol tertentu, pintu kurungan tersebut akan terbuka. Pada tes pertama, kucing dikondisikan 
dalam keadaan lapar dan diberikan sepotong makanan yang diletakkan di luar kotak. Setelah itu kucing tersebut menunjukkan respon yang agresif sampai akhirnya kucing itu menyentuh tombol kurungan dan keluar untuk menyantap makanan. Pada tes selanjutnya, kondisi kucing dibuat sama dengan saat tes pertama kali. Hasilnya kucing tersebut dapat keluar kotak lebih cepat dari tes pertama dan berhasil menyantap makanan.

Berdasarkan percobaan tersebut, Edward Lee Thorndike berkesimpulan bahwa belajar adalah hubungan antara stimulus dan respon. Itulah sebabnya teori koneksionisme juga disebut $S$ - $R$ bond theory dan $S$ - $R$ psychology of learning atau keduanya dikenal dengan trial and error learning. Eksperimen Edward Lee Thorndike terhadap kucing tersebut membuat kita mengetahui dua hal pokok yang mendorong timbulnya fenomena belajar.

Pertama, keadaan kucing yang lapar. Berkaitan dengan hal ini maka dapat dipastikan bahwa motivasi (seperti rasa lapar) merupakan hal yang sangat penting dalam belajar. Kedua, tersedianya makanan di depan pintu kotak merupakan efek positif yang dicapai oleh respon dan menjadi dasar timbulnya hukum belajar (law of effect).

\section{Hukum-hukum teori Edward Lee Thorndike}

1. Hukum kesiapan (law of readiness)

Hukum kesiapan (law of readiness) menjelaskan tentang kesiapan individu untuk melakukan suatu perbuatan. Penelitian yang dilakukan Thorndike terhadap kucing lapar tersebut menunjukkan bahwa kucing yang sedang lapar akan mudah bereaksi ketika melihat makanan yang diletakan di luar kotak tempat di mana kucing tersebut dikurung.

Dalam konteks pendidikan, salah satu hal penting yang bisa dilakukan pendidik adalah mengkondisikan keadaan peserta didiknya terlebih dahulu agar mereka siap sebelum menerima materi pelajaran. Pendidik bisa memberikan stimulus seperti motivasi belajar atau berkisah kepada anak agar suasana belajar tidak kaku dan menegangkan. Pendidik juga harus memperhatikan kondisi masingmasing peserta didiknya apakah saat itu ada yang sedang sakit, pusing, belum 
makan, dan lain sebagainya. Kondisi mental individu dalam belajar dapat mempengaruhi hasil belajar itu sendiri.

2. Hukum latihan (law of exercise)

Berdasarkan penelitian Edward Lee Thorndike terhadap kucing dapat ditarik sebuah kesimpulan bahwa hubungan antara stimulus dan respon akan menguat apabila ada latihan yang semakin sering dilakukan. Sebaliknya, hubungan antara stimulus dan respon akan semakin lemah jika tidak ada latihan.

Dalam proses belajar, semakin sering materi pelajaran diulang-ulang atau dipelajari, maka akan semakin kuat pula materi pelajaran itu melekat dalam diri peserta didik. Oleh karenanya variasi dalam proses pembelajaran sangat penting untuk diterapkan agar anak tidak mengalami kejenuhan atau kebosanan saat mengulang materi pelajaran yang telah diberikan.

3. Hukum akibat (law of effect)

Hukum akibat (law of effect) menunjukkan bahwa suatu perbuatan yang menimbulkan rasa puas atau senang akan cenderung dilakukan berulang kali. Sebaliknya, suatu perbuatan yang tidak menimbulkan rasa senang akan cenderung tidak diulang lagi.

Dalam konteks pembelajaran, hukum akibat (law of effect) bisa diterapkan untuk memacu motivasi belajar peserta didik. Hal ini bisa diaplikasikan melalui hadiah (reward) dan hukuman (punishment). Hadiah bisa mendorong motivasi para anak agar lebih giat dan bersungguh-sungguh dalam belajar. Sedangkan hukuman dapat membuat anak untuk tidak melakukan perbuatan yang tidak bermanfaat dalam proses belajar.

\section{Al Ghazali dan Teori Belajarnya}

Nama lengkap Al Ghazali adalah Abu Hamid Muhammad bin Muhammad bin Muhammad al Ghazali. Ia dilahirkan di kota Thus, Khurasan, Iran pada tahun 450 H/1058 M (Abu Hamid Muhammad al Ghazali, 2018). Al Ghazali merupakan seorang tokoh besar yang dikagumi bukan hanya di dunia Timur, tetapi juga di dunia Barat. Berbagai karya tulis telah dihasilkannya dalam berbagai bidang seperti filsafat, logika dan tasawuf, termasuk di dalamnya tentang pendidikan. Oleh karena itulah Al Ghazali 
digelari dengan hujjatul Islam. Ia wafat pada tahun $505 \mathrm{H} / 1111 \mathrm{M}$ pada usia 55 tahun (Yoke Suryadarma dan Ahmad Hifdzil Haq, 2015).

Al Ghazali belajar dengan Syaikh Ahmad ar Razakani di kampungnya, yakni Ghazalah yang berada di kawasan Thus sebuah kota di Iran. Kemudian ia melanjutkan perjalanan ke Jurjan dan berguru kepada Syaikh Abu Nashr al Isma'ili. Setelah itu beliau pergi ke Naisabur dan belajar kepada Imam Haramain al Juwaini. Setalah Imam Haramain wafat, Al Ghazali pergi ke Muaskar dan bertemu dengan Al Wazir (menteri) Nizam al-Mulk, Imam Al Ghazali kemudian diangkat oleh Al Wazir Nizam al-Mulk menjadi guru besar di Madrasah An Nizhamiyah di Baghdad pada usia 34 tahun. Al Ghazali mengajar di Madrasah An Nizhamiyah selama kurang lebih sepuluh tahun. Kemudian Al Ghazali meninggalkan Baghdad menuju masjid Jami' al Umawi, Damaskus. Saat berada di Damaskus inilah Al Ghazali menulis kitab Ihya Ulumiddin. Al Ghazali kemudian melanjutkan perjalanannya ke kampung asalnya dan tinggal di sana selama enam tahun. Setalah itu ia diminta oleh Fakhrul Mulk (putra Nizam al Mulk) untuk mengajar kembali di Madrasah An Nizhamiyah. Pada tahun $500 \mathrm{H}$ terjadi kekacauan yang menyebabkan terbunuhnya Fakhrul Mulk sehingga Al Ghazali memutuskan untuk kembali ke kampung asalnya. Kemudian ia mendirikan lembaga pendidikan di dekat rumahnya dan menghabisakan masa hidupnya dengan mengajar dan menulis kitab (Abu Hamid Muhammad al Ghazali, 2018).

Al Ghazali adalah tokoh yang memiliki pengaruh besar dalam sejarah Islam. Hal itu karena banyaknya kontribusi beliau dalam keilmuan Islam yang diwujudkannya dalam banyaknya buku yang ia tulis, dalam beberapa keilmuan yang tersebar dalam buku yang dituliskannya banyak terdapat pembahasan atau kajian tentang akhlak.

Ladzi Safroni (2013) menyebutkan bahwa tujuan utama mempelajari ilmu pengetahuan menurut Al Ghazali adalah untuk mencapai kesempurnaan dan keutamaan, yakni kesempurnaan dan keutamaan bidang di dunia dan mencapai kehidupan akhirat.

Akhlak adalah gambaran keadaan jiwa yang terinternalisasi, tempat perilaku disandarkan dengan mudah tanpa membutuhkan pemikiran dan pertimbangan lagi. perhatian Al Ghazali terkait metode pengajaran lebih terfokus untuk pendidikan agama bagi anak-anak. Dalam hal ini, Al Ghazali mencontohkan suatu metode keteladanan 
bagi mental anak-anak, pembinaan budi pekerti, dan penanaman sifat-sifat utama untuk mereka. Menurut Al Ghazali, akhlak perlu diajarkan dan dididikkan sejak dini sehingga seorang anak bisa mengetahui batasan perbedaan antara perbuatan yang baik dan buruk, sanggup merealisasikannya, serta dapat menilai kondisi keadaan akhlaknya apakah baik atau buruk (Syamsul Kurniawan, 2017).

Dalam Islam, akhlak memiliki kedudukan yang penting karena bisa memandu bagi kehidupan masyarakat. Menurut Itsna Safira dan Mizan Khairusani (2020) akhlak di dalam Islam juga untuk memelihara eksistensi manusia sebagai makhluk yang terhormat sesuai dengan fitrahnya.

Pendidikan Islam adalah upaya transformasi nilai-nilai yang sesuai ajaran Islam yang didasarkan pada al Quran dan sunnah Nabi Muhammad saw. sebagai teladan utama. Pemikiran pendidikan Al Ghazali secara umum bersifat religius-etis, sehingga pendidikan yang benar merupakan sarana untuk mendekatkan diri kepada Allah agar bisa menggapai kebahagiaan di dunia dan akhirat (Ary Antony Putra, 2016).

Metode pendidikan yang dipakai oleh Al Ghazali adalah mujahadah dan riyadhah, yakni pendidikan praktik kedisiplinan, pembiasaan dan penyajian dalil naqli dan aqli, serta bimbingan dan nasihat. Al Ghazali juga sepakat dengan adanya pujian dan hukuman untuk mendukung terciptanya akhlak mulia (Hanapi, 2017:91). Adanya pujian dan hukuman (rewards and punishment) dalam belajar yang disebutkan $\mathrm{Al}$ Ghazali ini memiliki kesamaan dengan law of effect yang didasarkan penelitian Edward Lee Thorndike.

Ary Antony Putra (2016) menyebutkan faktor-faktor pendidikan menurut Al Ghazali: (a) Tujuan menuntut ilmu adalah untuk meraih kebahagiaan hidup di dunia dan akhirat, sehingga yang menjadi landasan utama adalah al Quran dan sunnah. (b) Seorang pendidik harus mempunyai niat untuk mendekatkan diri kepada Allah, bisa menjadi teladan bagi anak didiknya, kompeten dengan ilmu yang diajarkannya, objektif, dan menyayangi semua anak didiknya dengan baik. (c) Anak didik harus berniat mendekatkan diri pada Allah dan menjauhi maksiat, menghormati gurunya, dan rajin belajar. (d) Kurikulum disesuaikan dengan perkembangan anak. Materi pelajaran diberikan secara bertahap dari yang mudah menuju materi yang lebih sulit, materi tahuid hendaknya dijadikan landasan utama. Bentuk-bentuk kurikulum pendidikan dapat dicontohkan dengan perintah atau larangan, dorongan, hambatan, 
nasihat, anjuran, hadiah, hukuman, pemberian kesempatan atau menutupnya. (e) Lingkungan pendidikan baik dalam keluarga, sekolah, dan masyarakat hendaklah lingkungan yang mendukung ke arah yang lebih baik.

Masa anak-anak sangat penting bagi Al Ghazali, karena pada mulanya anak adalah murni dan terbuka terhadap pengaruh lingkungan. Anak seperti kertas putih sehingga masa depannya ditentukan oleh pendidikan dan pendidik yang mempengaruhinya (Elfa Yuliana dan Reza Wahyu, 2019). Menurut Evi Aeni (2018) dalam pembentukan akhlak, cara yang digunakan adalah keteladanan (uswah hasanah) dengan menjadikan nabi Muhammad sebagai role model utama sebagaimana teknik yang dikemukakan oleh $\mathrm{Al}$ Ghazali, yaitu dengan mengosongkan diri dari sifat tercela (takhalli), menghiasi diri dengan sifat terpuji (tahalli), dan mengangungkan Allah (tajalli).

\section{Teori Belajar Edward Lee Thorndike dan Al Ghazali dalam implementasinya pada pembelajaran anak}

Teori belajar Edward Lee Thorndike lebih menekankan pada peristiwa belajar yang bisa diterima oleh akal dan dapat dibuktikan melalui pancaindera (rasional-empiris). Sedangkan teori belajar yang diusung oleh Al Ghazali tidak hanya memberikan perhatian pada peristiwa belajar yang bersifat rasional-empiris, akan tetapi juga memberikan perhatian yang bersifat normatif-kualitatif.

Teori belajar behavioristik seperti yang dicetuskan oleh Edward Lee Thorndike mendefiniskan bahwa belajar adalah perubahan tingkah laku yang bisa diamati secara langsung sebagai akibat dari adanya stimulus-stimulus dan respon-respon menurut prinsip mekanistik yang bisa dilihat dari metode belajar trial and error. Selain itu, Edward Lee Thorndike juga menggunakan reinforcement (peneguh)/satisfiyer (pembawa kepuasan). Artinya individu akan belajar jika ia mendapatkan reinforcement, jika tidak ada reinforcement yang akan didapatkan, maka belajar tidak jadi dilakukannya.

Teori belajar Behavioristik yang didasarkan pada penelitian yang dilakukan oleh Edward Lee Thorndike secara implisit bersifat materialistik. Artinya, binatang yang dijadikan bahan penelitiannya mau melakukan usaha trial and error karena ingin mendapatkan makanan yang ada di luar kotak (reinforcement). Dengan demikian, teori 
belajar yang dicetuskan oleh Edward Lee Thorndike selain dalam rangka pembentukan kebiasaan, juga bisa dikatakan bersifat materi. Meski demikian, hasil penelitian yang dihasilkan oleh Edward Lee Thorndike ini tidak ditolak begitu saja. Karena dengan adanya reinforcement bisa digunakan sebagai motivasi atau pendorong bagi individu untuk belajar.

Dalam teori belajar behavioristik peran guru sangat dominan dalam pembelajaran (teacher center learning). Artinya seorang guru harus memiliki kesiapan dan bekal ilmu yang mencukupi untuk mendidik anak -anak nya. Ibarat teko dan gelas, teko harus berisi terlebih dahulu untuk bisa mengisi gelas tersebut, dan gelas agar bisa diisi haruslah dalam keadaan terbuka. Agar tujuan pembelajaran dapat tercapai, guru dan anak harus sama-sama dalam keadaan siap untuk melakukan proses pembelajaran (law of readiness).

Hukum law of readiness dalam belajar sesuai dengan pemikiran Al Ghazali bahwa seorang pendidik haruslah memiliki pengetahuan yang baik (kompeten) agar bisa merumuskan metode dan materi yang sesuai dengan intelektual peserta didiknya.

Anak yang memiliki kemuan kuat untuk mencari ilmu ibarat gelas terbuka yang sudah siap diisi air. Terbuka di sini bukan hanya terbuka tanpa tutup secara fisik, tetapi niat atau motivasi juga benar-benar telah ada. Anak yang dikatakan siap menuntut ilmu bukan sekedar datang secara fisik, tetapi datang dengan segenap kesadaran untuk menuntut ilmu.

Dalam Islam selalu dianjurkan untuk berdoa terlebih dahulu sebelum menuntut ilmu, hal ini selain memohon ilmu yang bermanfaat pada Allah, berdoa juga sebagai upaya untuk menghadirkan kesadaran individu ketika menuntut ilmu. Dengan demikian, tujuan pendidikan seperti yang disebutkan oleh Al Ghazali, yakni untuk mendekatkan diri pada Allah bisa direalisasikan.

Dalam banyak hal, belajar tidak cukup hanya dilakukan satu kali. Seperti saat pertama kali seseorang belajar mengendarai sepeda, mula-mula ia akan terjatuh, tetapi dengan kegigihan untuk tidak mudah menyerah walau berulang kali terjatuh, akhirnya kemampuan untuk bisa mengendarai sepeda dapat dikuasai. Dalam Islam, untuk dapat bersikap ramah (friendly) kepada sesama haruslah dibiasakan setiap hari. Contonya seperti tersenyum, orang yang tak biasa tersenyum kepada sesama saat bertemu tentu akan sulit melakukannya saat tiba-tiba diminta tersenyum, atau ia tersenyum namun 
senyumnya tersebut terlihat kalau dibuat-buat. Dari contoh sederhana ini menunjukkan pentingnya membiasakan hal-hal baik dalam pembelajaran (law of exercise).

Untuk dapat menumbuhkan dan menjaga motivasi belajar agar tetap tinggi, maka sangat perlu adanya reward atau stimulus yang membantu anak untuk tetap bersemangat dalam menuntut ilmu. Reward atau hadiah tidak melulu harus berbentuk barang, tetapi bisa berupa apresiasi dan hati yang pandai menghargai setiap potensi. Dalam Islam, selain motivasi reward akhirat (tsawab al-akhirah), reward di dunia (tsawab ad-dunya) juga penting diberikan kepada anak agar tidak mudah patah semangat. Dengan adanya motivasi (law of effect) ini diharapkan kualitas pembelajaran menjadi lebih baik. Hasil dari pembelajaran yang telah dilakukan dengan baik akan terlihat dari adanya perubahan perilaku anak menjadi lebih baik pula. ALGhazali terhadap pendidikan bahwasanya dalam mendidik anak hendaknya pendidikan selalu disesuaikan dengan tahap-tahap perkembangan anak seperti perkembangan kognitif dan moralnya. Karena pendidikan merupakan proses yang sinergis antara pendidik, peserta didik, metode dan materi.

\section{SIMPULAN}

Proses belajar trial and error yang dilakukan dengan memberikan stimulus untuk mendapatkan respon yang diharapkan bisa dipakai untuk memberikan motivasi belajar anak. Selain itu, agar bukan sekedar mekanistik mengingat anak bukanlah robot yang tidak memiliki rasa, maka anak juga harus dibekali dengan nilai-nilai religius yang bisa memberikan motivasi dari dalam diri anak itu sendiri. Karena tugas pendidik adalah membantu anak mengembangkan seluruh potensi yang ia miliki hingga mencapai kedewasaan dan anak adalah sebagai pihak yang potensinya perlu dikembangakan maka segala sesuatu yang akan dirumuskan oleh pendidik baik metode maupun materi haruslah mengacu pada anak yaitu pada aspek perkembangannya yang selalu berdasarkan pada pembentukan akhlak.

\section{UCAPAN TERIMA KASIH}

Peneliti mengucapkan terima kasih sedalam-dalamya kepada Allah SWT atas limpahan karunia dan hidayanya sehingga penulis dapat menyelesaikan karya ilmia ini, serta pengelola jurnal ABATA yang telah menerbitkan artikel ini. 


\section{REFERENSI}

Al Ghazali, Abu Hamid Muhammad. 2018. Ayyuhal Walad, terj. Ahmad Fahmi bin Zamzam. (Kedah: Khazanah Banjariah Maahad Tarbiah Islamiah.

Anwar, Chairul. 2017. Buku Terlengkap Teori-teori Pendidikan Klasik hingga Kontemporer. Yogyakarta: IRCiSoD.

Hanapi. 2017. Konsep Pendidikan Menurut Imam Al-Ghazali. El-Hikam: Jurnal Pendidikan dan Kajian Keislaman. Vol. X. No. 1.

Hermansyah. 2020. Analisis Teori Behavioristik (Edward Thorndike) dan Implementasinya dalam Pembelajaran SD/MI. Modeling: Jurnal Program Studi PGMI. Vol. 7. No. 1.

Kurniawan, Syamsul. 2017. Pendidikan Karakter dalam Islam, Pemikiran Al Ghazali tentang Pendidikan Karakter Anak Bebasis Akhlaq al-Karimah. Tadrib. Vol. 3. No. 2.

Makki, Ali. 2019. Mengenal Sosok Edward Lee Thorndike Aliran Fungsionalisme dalam Teori Belajar. Pancawahana: Jurnal Studi Islam. Vol. 14. No.1.

Mulyono. 2012. Strategi Pembelajaran Menuju Efektivitas Pembelajaran di Abad Global. Malang: UIN Maliki Press,.

Muslih, Mohammad. 2018. Rekontsruksi Nalar Keagamaan; Ikhtiar Menemukan Konteks Agama Bagi Pengembangan Sains. Jurnal Afkaruna. Vol. 14. No. 2.

Nahar, Novi Irwan. 2016. Penerapan Teori Belajar Behavioristik dalam Proses Pembelajaran. Nusantara: Jurnal Ilmu Pengetahuan Sosial, Vol. 1.

Pane, Aprida dan Muhammad Darwis Dasopang. (Desember 2017). Belajar dan Pembelajaran. Fitrah: Jurnal Kajian Ilmu-ilmu Keislaman, Vol. 03, No. 2.

Putra, Ary Antony. 2016. Konsep Pendidikan Agama Islam Perspektif Imam AlGhazali. Al-Thariqah. Vol. 1. No. 1.

Rufaedah, Evi Aeni. 2018. Teori Belajar Behavioristik Menurut Perspektif Islam. Risalah Jurnal Pendidikan dan Studi Islam. Vol. 4. No. 1.

Rusuli, Izzatur. 2014. Refleksi Teori Belajar Behavioristik dalam Perspektif Islam. Jurnal Pencerahan. Vol. 8. No. 1.

Safira, Itsna dan Mizan Khairusani. 2020. Teori Ta'dib Syed Muhammad Naquib alAttas dan Relevansinya dalam Pendidikan Karakter Islam Kontemporer. Jurnal Pendidikan: Riset dan Konseptual. Vol. 4. No. 4.

Safroni, Ladzi. 2013. Al-Ghazali Berbicara tentang Pendidikan. Yogyakarta: Aditya Media Publishing.

Suryadarma, Yoke dan Ahmad Hifdzil Haq. 2015. Pendidikan Anak Menurut Imam Al Ghazali. At-Ta'dib. Vol. 10. No. 2.

Thoifuri. 2013. Menjadi Guru Inisiator. Semarang: Media Campus Publishing.

Yuliana, Elfa dan Reza Wahyu Al-Hadi Abror. 2019. Komparasi Pemikiran AlGhazali dan John Locke Pespektif Pendidikan Islam dan Barat. Tarbawi. Vol. 4. No. 1. 